\title{
Magnetic force: an attractive solution for penetrating metallic foreign body removal in neck and in ENT
}

\begin{abstract}
A 16-year-young boy presented to our ENT department OPD with history of a penetrating metallic foreign body in the neck since $2.5 \mathrm{yrs}$. On wound exploration under local anesthesia, the foreign body was not identified. It was removed with the help of a magnet after 2.5 years.
\end{abstract}

Keywords: metallic foreign body, magnet,neck
Volume 8 Issue 5 - 2017

\author{
Chintale Sambhaji Govind, Kirdak Vilas \\ Rambhau, Jatale Sonali Praful, Shaikh Kaleem \\ ENT Department Maharashtra University of Health Sciences \\ jiius' limsr College and Noor Hospital, India
}

\begin{abstract}
Correspondence: Chintale sambhaji govind, Assistant professor, ENT Department, Jiius' limsr College and Noor Hospital, Badnapur, Dist jalna 43।202, Maharashtra, India, Tel 91+9970323030,Email Drsamchinto@gmail.com
\end{abstract}

Received: August 02, 2017 | Published: September 21, 2017
Abbreviations: ENT, ear nose throat; OPD, outpatient department; CT, computed tomography

\section{Introduction}

Penetrating Neck Injuries are present in $5-10 \%$ of all trauma cases. Some kinds of materials such as Knife, bullet, metallic rod, pencil, fragments of glass, iron nail chips, wooden stick etc. can cause penetrating neck injury. Such injuries can damage vital structures present in the neck like great vessels, nerves, pharynx, esophagus etc. and threaten life. We present the case of 16yrs. Patient who had an unusual penetrating neck injury caused when patient were hammering over iron nail and iron particle of that nail get penetrated in anterior aspect of neck

\section{Case report}

A 16-year-young boy, a farmer by occupation was referred to our ENT department OPD with history of foreign body in the neck. Patient had been hammering on a nail in his farm that shattered on impact and got stuck up in the neck 2.5 year back. He attended a local general physician where his wound was cleaned and dressed and was discharged with antibiotics and analgesics. After 2.5years, he developed throbbing pain in front of his neck and discharge from the wound site. He consulted at our ENT department OPD we explored the wound but attempt was not successful so we discharge the patient and advised him to use magnet for long duration as magnetic force action will take place and foreign body if any remains in soft tissue will come to skin or in subcutaneous plane. Really after 5month of use of magnet daily to move on anterior aspect of neck for 8 to 10time per day patient again come to our OPD for follow up. On 70degree laryngoscope examination were normal, no intraluminal foreign body was found. On investigating with $\mathrm{x}$-ray soft tissue neck lateral view (Figure 1a). On examination of neck small protruding swelling seen (Figure 1b). On palpation approximately it was size of $0.5 \mathrm{mmx} 0.5 \mathrm{~mm}$.

After all routine blood investigations, his wound was planned to explore under local anesthesia but on the day of operation patient again used a big magnet once over anterior aspect of neck and foreign body is automatically come on magnet (Figure 1c). It was fruitful decision to give high Magnetic force magnet to patient (Figure 1d).

\section{Discussion}

Foreign body neck is a common case presenting to ENT surgeons. Its immediate removal is a must, or else complications can occur. Few penetrating metallic foreign body can migrate along subcutaneous and facial planes to adjacent structures and even to thyroid gland. Our defense mechanism of the body to the foreign body cause invasion of inflammatory cells leading to granuloma formation. The foreign body can act as foci of recurrent infection and can cause abscesses. Abscess might rupture and subsequently a sinus can form. Persistent irritation and infection by the foreign body can cause great vessel rupture which ends fatally. All penetrating neck wounds are potentially dangerous and require emergency treatment because of the presence of vital structures in the neck, which can be divided into the following four groups1; (i) the air passages: trachea, larynx, lungs; (ii) vascular structures: carotid, jugular, subclavian, innominate and aortic arch vessels; (iii) gastrointestinal structures: pharynx and oesophagus and (iv) neurological structures: cranial nerves, peripheral nerves, brachial plexus and spinal cord. Objects penetrating through the neck could damage any of these structures. Moreover, the injury in the zone III (area above the level of angle of mandible) is more dangerous than injury in the zone II (the area between the cricoid cartilage and angle of the mandible) because of proximity of skull base to zone III. ${ }^{1}$ For zone II injury either exploration. ${ }^{2}$ A recent study by Nunez et al has emphasized the use of contrast enhanced CT angiography as a noninvasive alternative to conventional angiography ${ }^{3}$. Studies have shown that there is no significant difference between clinical examination and angiography for detection of vascular injury in zone II penetrating neck injuries. It is also seen that findings on physical examination are good predictors of arterial injury in patients with penetrating neck wounds and can exclude injury in over $99 \%$ of patients. ${ }^{4}$ In a recent study done by Saharan et al on 145 patients with zone II penetrating neck trauma, it was found that physical signs of vascular injury like active bleeding, expanding hematoma, bruit, pulse deficit, central neurologic deficit etc. could accurately detect vascular injury with missed injury rate of $0.7 \%$ which is comparable to arteriography in accuracy but less costly and noninvasive. ${ }^{5}$ The present case had no physical signs of major vessels injury; so extensive investigations were not done apart from the $\mathrm{x}$ ray neck to get some information on the anatomical relationship of the foreign body 
with other structure in the neck. Exploration of neck is considered mandatory by many surgeons but a selective approach is considered appropriate by others.

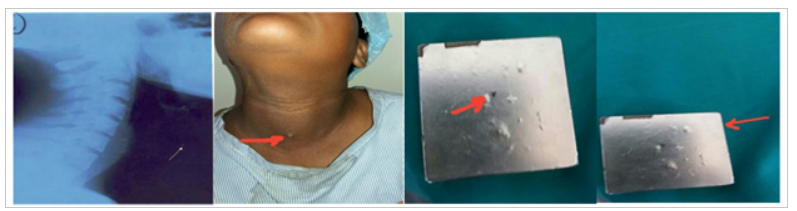

Figure I [a]: X-ray view, [b]: Fb in neck, [c]: Fb over magnet, [d]: Magnet.

Considering the morbidity and mortality associated with surgical exploration. ${ }^{6,7}$ Removal of foreign bodies which break up into fragments such glasses, shotgun pellets etc. is more difficult as there are chances of some fragments being left Organic foreign bodies like the piece of branch of tree are grossly contaminated and can cause serious infection if not removed promptly and not treated with adequate antibiotic coverage . so in this case were metallic foreign body get stuck in to neck we advised the patient to use strong metal use over period for avoiding neck exploration surgery to remove it and foreign body itself will come to skin surface with help of strong magnet and yes its came to surface and get removed.

\section{Conclusion}

Magnet is great tool it's a handy and very simple instrument for removal of metallic foreign body anywhere in the body, without subjecting the patient to the harmful effects of radiation by $\mathrm{C}$ arm some time costly invasive radiological investigations and surgical procedure may be avoided for very tiny foreign body some time that cannot be traced on exploration. Hence it is a very important tool in the armamentarium of ENT surgeons.

\section{Acknowledgements}

This case is reported at our institute Jiius iimsr warudi tq badnapur dist. jalna thanks to our teachers and colleague for supporting this case report making.

\section{Conflicting interest}

Author declares there are no conflicts of interest.

\section{Funding}

None.

\section{References}

1. Maisel HM, Hom DB. Penetrating trauma to the neck. In: Fredrickson JM, et al. (Eds,). Otolaryngology Head and Neck Surgery. St louis: Mosby, USA. 1998. p.1707-1720.

2. Miller RH, Duplechain JK. Penetrating wounds of the neck. Otolaryngol Clin North Am. 1991;24:15-29.

3. Nunez DB, Torres-Leon M, Munera F. Vascular injuries of neck and thoracic inlet: helical CTangiographic correlation. Radiographics. 2004;24(4):1087-1098.

4. Beitsch P, Weigelt JA, Flynn E, Easley S. Physical examination and arteriography in patients with penetrating zone II neck wounds. Arch Surg. 1994; 129(6): 577-581.

5. Sekharan J, Dennis JW, Veldenz HC, et al. Continued experience with physical examination alone for evaluation and management of penetrating zone 2 neck injuries: results of 145 cases. J Vasc Surg. 2008;32(3):483-489.

6. Rodriguez Gomez E. Cervical foreign body. An unusual case. Acta Otorinolaringol Esp. 2004;55(6):298-301.

7. Hersman G, Barker P, Bowley DM, et al. The management of penetrating neck injuries. Int Surg. 2001; 86(2):82-89. 